\title{
Research Trends in Artificial Intelligence Applications in Human Factors Health Care: Mapping Review
}

Onur Asan, $\mathrm{PhD}$; Avishek Choudhury, MSc

School of Systems and Enterprises, Stevens Institute of Technology, Hoboken, NJ, United States

Corresponding Author:

Onur Asan, $\mathrm{PhD}$

School of Systems and Enterprises

Stevens Institute of Technology

1 Castle Point Terrace

Hoboken, NJ, 07030

United States

Phone: 14145264330

Email: oasan@ stevens.edu

\section{Abstract}

Background: Despite advancements in artificial intelligence (AI) to develop prediction and classification models, little research has been devoted to real-world translations with a user-centered design approach. AI development studies in the health care context have often ignored two critical factors of ecological validity and human cognition, creating challenges at the interface with clinicians and the clinical environment.

Objective: The aim of this literature review was to investigate the contributions made by major human factors communities in health care AI applications. This review also discusses emerging research gaps, and provides future research directions to facilitate a safer and user-centered integration of AI into the clinical workflow.

Methods: We performed an extensive mapping review to capture all relevant articles published within the last 10 years in the major human factors journals and conference proceedings listed in the "Human Factors and Ergonomics" category of the Scopus Master List. In each published volume, we searched for studies reporting qualitative or quantitative findings in the context of AI in health care. Studies are discussed based on the key principles such as evaluating workload, usability, trust in technology, perception, and user-centered design.

Results: Forty-eight articles were included in the final review. Most of the studies emphasized user perception, the usability of AI-based devices or technologies, cognitive workload, and user's trust in AI. The review revealed a nascent but growing body of literature focusing on augmenting health care AI; however, little effort has been made to ensure ecological validity with user-centered design approaches. Moreover, few studies $(\mathrm{n}=5$ against clinical/baseline standards, $\mathrm{n}=5$ against clinicians) compared their AI models against a standard measure.

Conclusions: Human factors researchers should actively be part of efforts in AI design and implementation, as well as dynamic assessments of AI systems' effects on interaction, workflow, and patient outcomes. An AI system is part of a greater sociotechnical system. Investigators with human factors and ergonomics expertise are essential when defining the dynamic interaction of AI within each element, process, and result of the work system.

(JMIR Hum Factors 2021;8(2):e28236) doi: 10.2196/28236

\section{KEYWORDS}

artificial intelligence; human factors; health care systems; ecological validity; usability; trust; perception; workload

\section{Introduction}

\section{Influx of Artificial Intelligence in Health Care}

The influx of artificial intelligence (AI) has been shifting paradigms for the last decade. The term "AI" has been often used and interpreted with different meanings [1], and there is a lack of consensus regarding AI's definition [2]. In general, AI can be defined as a computer program or intelligent system capable of mimicking human cognitive function [3]. Over the years, the capabilities and scope of AI have substantially increased. AI now ranges from algorithms that operate with predefined rules and those that rely on if-then statements (decision tree classifiers) [4] to more sophisticated deep-learning 
algorithms that have the capabilities to automatically learn and improve through statistical analyses of large datasets [5,6]. There have been many studies and advancements with AI as it continues to evolve in numerous domains, including health care. AI applications such as MelaFind, a virtual assistant software, and IBM Watson have been introduced to improve health care systems, foster patient care, and augment patient safety [7]. AI applications have been developed and studied for every stakeholder in health care, including providers, administrators, patients, families, and insurers. In some specific areas such as radiology and pathology, there are strong arguments that AI systems may supersede doctors as a result of studies showing that $\mathrm{AI}$ algorithms outperformed doctors in accurately detecting cancer cells [8-10].

Further, developments in AI-enabled health information technologies (eg, AI-enabled electronic health records [EHRs] or clinical decision support systems) have benefitted from the availability of big data to predict clinical outcomes and assist providers in parsing through their EHRs to find individual pieces of medical information [11]. Despite AI having great potential, it is still in its infancy. The existing clinical AI systems are far from perfect for several well-known reasons, including (a) discriminatory biases coming from the input data; (b) lack of transparency in AI decisions, particularly neural networks, due to the black-box nature; and (c) sensitivity of the resulting decisions to the input data $[6,12]$.

\section{Typical AI-User Interactions}

AI systems are complex in the sense of being a black box for the users who might not have adequate expertise in statistics or computer science to be able to comprehend the functioning of AI. Thus, AI can undesirably complicate the relationships between users and computer systems if not well designed. Unlike other health care technologies, AI can interact (eg, through chatbots, automated recommender systems, health apps) with clinicians and patients based on the inputs (feedback) that it receives from the user, thus creating what we refer to as "the interaction loop." Unlike non-AI technologies, AI's output (result generated by the AI) largely depends on the information fed into it; for instance, in AI-based reinforcement learning [13], the system may learn and adapt itself based on user input. Therefore, the human-AI interaction may influence the human as well as the AI system: the user feeds AI with some information; the AI learns from this information, performs analyses, and sends an output to the user; the user receives the output, comprehends it, and acts accordingly; and the new data generated by the user's action goes back to the AI. Figure 1 illustrates three fundamental and typical interaction loops highlighting fundamental plausible transactions among clinicians, patients, and the AI system, in which the AI technology (such as Apple Watch) continuously measures the user's health information (heart rate, oxygen level) and sends the data to the user's health care provider. The care provider can then make treatment plans or clinical recommendations based on the AI results, which will then influence user health or health-related behavior (Loop 1). Other common user-AI interactions can be observed in online health services in which the user interacts with an AI-enabled chatbot for preliminary diagnoses (Loop 2). The third, but less common, user-AI interaction is when a doctor and patient together leverage an AI system for obtaining a better diagnosis in a clinical environment (Loop 3). For all of these applications, it is essential for the users to make a correct interpretation of AI outcomes, and to have a basic understanding of AI requirements and limitations. The optimum and successful user-AI interaction depends on several factors, including the physical (eg, timely access to technology, and visual and hearing ability, particularly of patients), cognitive (eg, ability to comprehend AI functioning, ability to reason and use AI-enabled devices), and emotional (eg, current state of mind, willingness to use AI, prior experience with AI technology) resources of people (eg, health professionals and caregivers). 
Figure 1. User-artificial intelligence (AI) interaction loops.

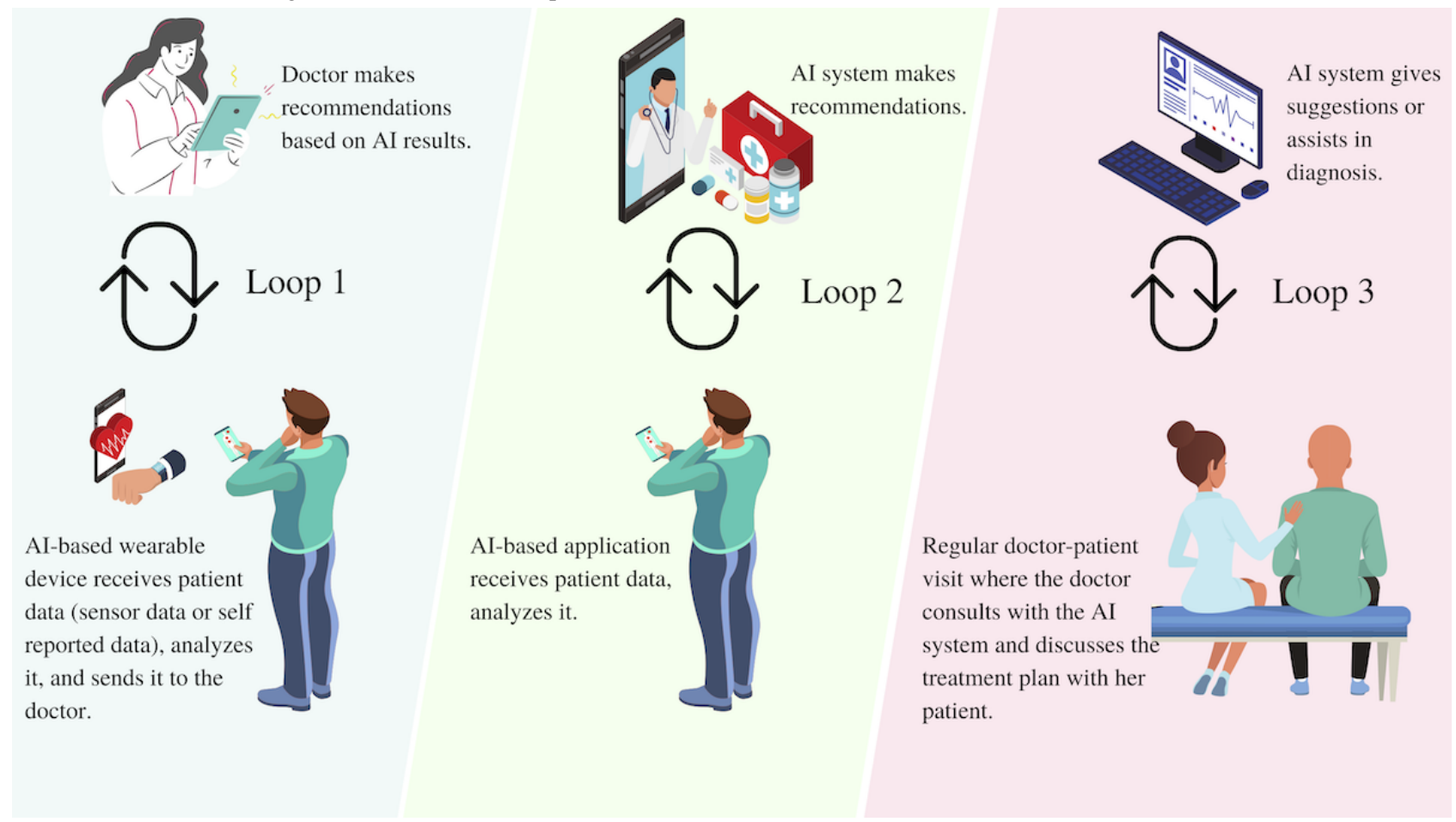

\section{Efforts to Improve AI and the Essential Role of Human Factors}

The developers of health care AI apps have primarily focused on AI's analytical capabilities, accuracy, speed, and data handling (see Figure 2) and have neglected human factors perspectives, which lead to poorly designed apps [14]. Although recent studies have reported the impact of biased data [15], as well as interpretability, interoperability, and lack of standardization $[7,16]$ on AI outcomes, very few have acknowledged the need to assess the interactions among AI, clinicians, and care recipients.

Recently, as acknowledged in the Annual Meetings of the Human Factors Ergonomics Society [17,18], increasing autonomous activities in health care can pose risks and concerns regarding AI. Therefore, there is a need to integrate human factors and ergonomics (HFE) principles and methods into developing AI-enabled technologies for better use, workflow integration, and interaction. In health care AI research, two factors have not been sufficiently addressed by researchers, namely ecological validity and human cognition, which may create challenges at the interface with clinicians as well as the clinical environment and lead to errors. Moreover, there is insufficient research focusing on improving the human factors, mainly (a) how to ensure whether clinicians are implementing the AI correctly, (b) the cognitive workload it imposes on clinicians working in stressful environments, and (c) its impact on clinical decision-making and patient outcome. The inconvenient truth is that most of the AI showing prominent ability in research and the literature is not currently executable in a clinical environment $[19,20]$. Therefore, to better identify the current state of HFE involvement in health care AI, we performed a mapping review of studies published in major human factors journals and proceedings related to AI systems in health care. The aim of the mapping review was to highlight what has been accomplished and reported in HFE journals and discuss the roles of HFE in health care AI research in the near future, which can facilitate smoother human-system interactions. 
Figure 2. Illustrating some of the research objectives of experts in human factors and artificial intelligence.

Human Factors Optimize

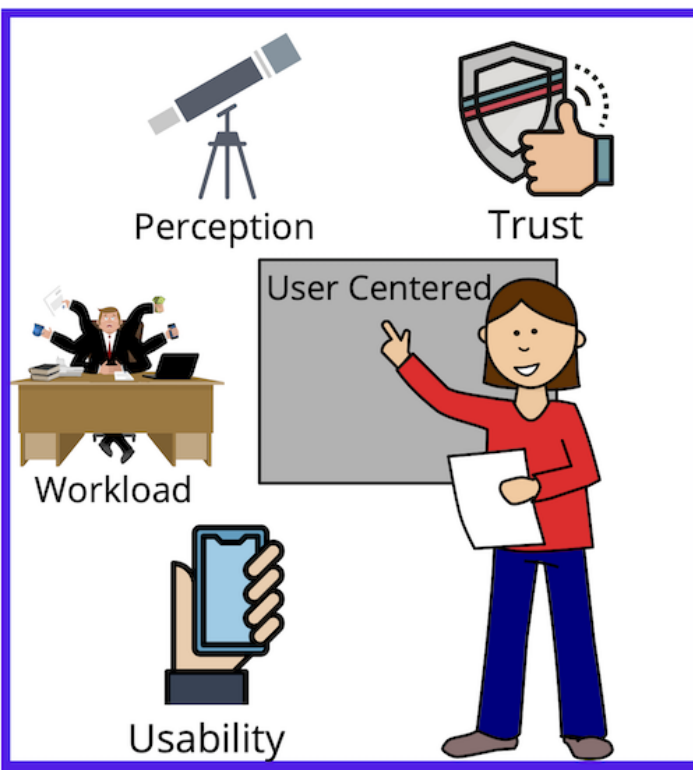

\section{Methods}

\section{Design and Data Source}

We performed a mapping review to explore the trending and initial areas regarding health care AI research in HFE publications. Our protocol was registered with the Open Science Framework on October 2, 2020 [21]. Mapping reviews are well-developed approaches to cover the representative literature (not exhaustive) for exploring and demonstrating trends in a given topic and time duration [22]. In this study, we selected major human factors journals and conferences that potentially publish health care-related work as our data source. Our selection of journals and conferences was guided by the "Human Factors and Ergonomics" category of the Scopus Master List and Scimago Journal \& Country Rank. We also added two journals that potentially publish patient safety-related human factors work: Journal of Patient Safety and BMJ Quality and Safety. In total, we explored 24 journals and 9 conference proceedings (see Multimedia Appendix 1). All the authors approved the final list of journals and conferences with consensus.

\section{Inclusion and Exclusion Criteria}

We performed an extensive manual search to capture all relevant articles published in English within the last 10 years (January 2010 to December 2020) in the journals and conference proceedings listed in Multimedia Appendix 1. In each published volume, we searched for studies reporting qualitative or quantitative findings in the context of $\mathrm{AI}$ in health care. The selected studies needed to (1) be framed in the context of health care; (2) cover an AI algorithm or AI-enabled technology such as machine learning, natural language processing, or robotics; and (3) report either qualitative or quantitative findings/outcomes. We only included journal papers and full

\section{Artificial Intelligence}

Optimize

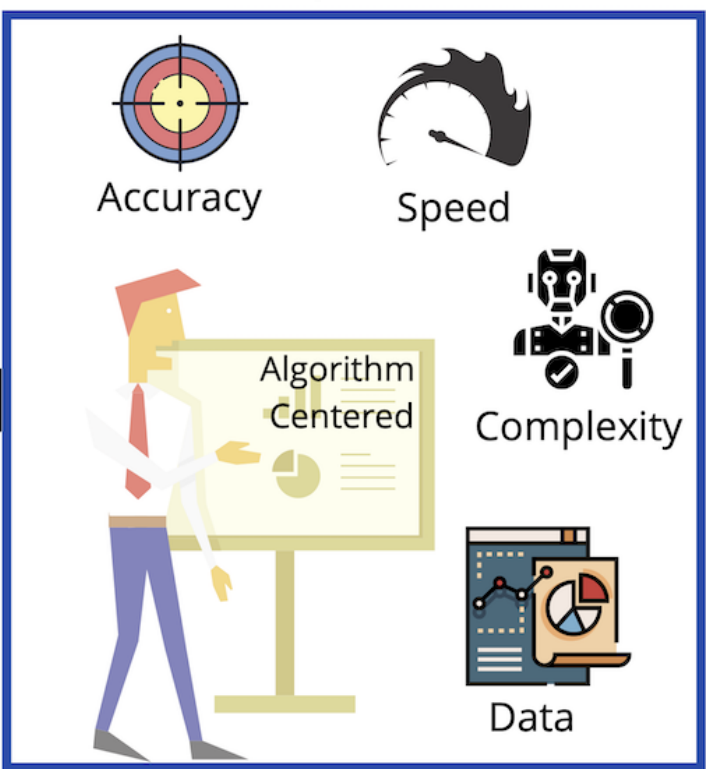

conference proceeding papers. Other materials such as conference abstracts, editorials, book chapters, poster presentations, perspectives, study protocols, review papers, and gray literature (eg, government reports and policy statement papers) were excluded.

\section{Paper Selection and Screening}

Articles in the journal and conference list were manually screened by two reviewers (AC and a research assistant) based on titles and abstracts using one of the inclusion criteria (ie, to be framed in the context of health care). We exported all of the retrieved publications to Sysrev software. In the second step, we excluded all ineligible publications (eg, reviews, short abstracts, and posters), as explained in the preceding section. In the last step, two reviewers (AC and a research assistant) independently screened all of the selected full papers based on the remaining two inclusion criteria: (1) covering an AI algorithm or AI-enabled technology such as machine learning, natural language processing, or robotics; and (2) reporting either qualitative or quantitative findings/outcomes. The reviewers also confirmed that the studies were framed in a health care context. The reviewers achieved $82 \%$ agreement. The lead researcher (OA) then resolved all conflicts, screened all of the shortlisted full-text articles, and finalized the article selection.

\section{Data Extraction and Analysis}

We followed a similar data extraction approach and analysis as reported by Holden et al [23]. Metadata (author names, the title of the paper, abstract) for each of the included articles were recorded in a standard Excel sheet. In our analysis, both authors (AC and OA) coded each included paper on different dimensions such as (1) sample/participant type, (2) AI system used, (3) source of data collection, and (4) objective and outcomes. Studies were also discussed based on the HFE principles such as evaluating workload, usability, trust in technology, 
perception, and user-centered design. These HFE principles and subcategories for the dimensions were derived from the final selected papers and were checked for face validity by the researchers. We iteratively worked on the data extraction process and revised the categories to achieve a final consensus.

Figure 3. Selection and exclusion process. AI: artificial intelligence.

\section{Results}

\section{Summary of Included Studies}

Figure 3 illustrates the screening and selection process. As a result of screening 24 selected journals and 9 conference proceedings (Multimedia Appendix 1), we finalized 48 articles matching our inclusion criteria, which were included in the scoping review with consensus from all reviewers. These 48 articles were published in 10 journals and 3 conference proceedings, as illustrated in Figure 4.

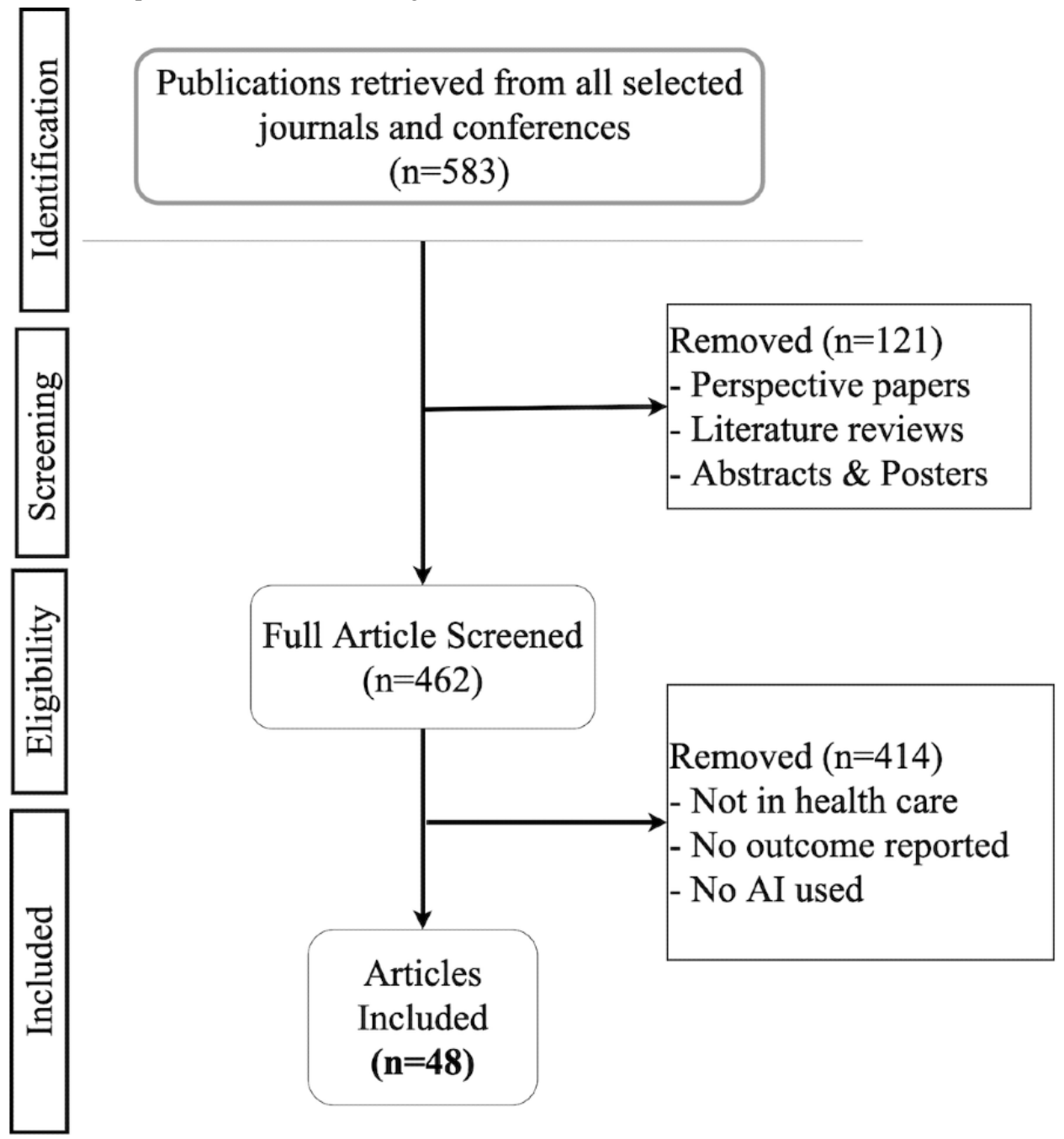


Figure 4. Overview of selected publications and their venues.

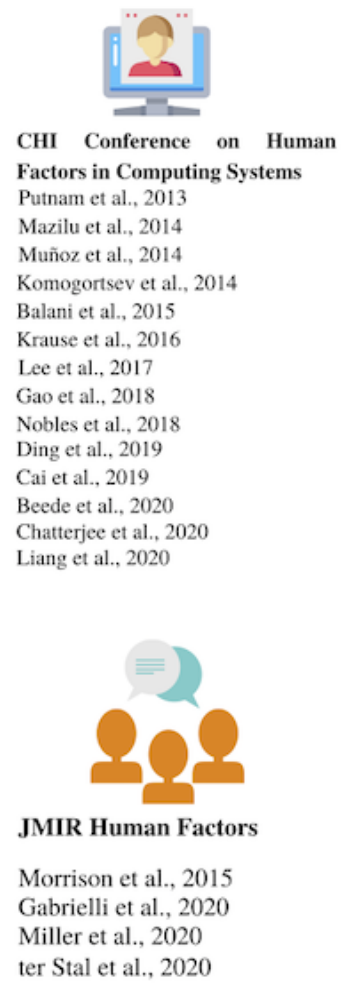

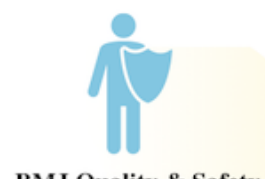

BMJ Quality \& Safety

Ong et al., 2010

Hawkins et al., 2016

Wagland et al., 2016

Wang et al., 2019

Bailey et al., 2020

Carayon et al., 2020

Parekh et al., 2020

Valik et al., 2020

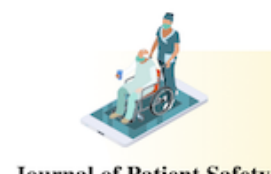

McKnight, 2012

Shiner et al., 2016

Moore et al., 2017

Moore et al., 2017
Marella et al., 2017

Jin et al., 2018

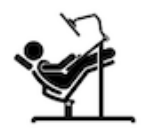

Ergonomics Hu et al., 2018 Ladstätter et al., 2016 Ladstätter et al., 2010

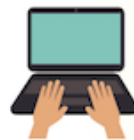

Computers in Human Behavior

Park et al., 2018

Sonğur \& Top, 2016

Aldape-Pérez et al., 2015

Cvetković \& Cvetković, 2017

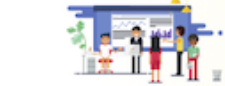

Proceedings of the Human Factors and Ergonomics Society Annual Meeting

Pryor et al., 2019

Kandaswamy et al., 2019

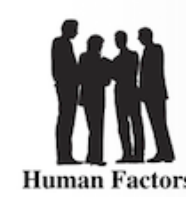

Azari et al., 2019

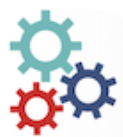

IEEE Transactions on HumanMachine Systems

Xiao et al., 2016

Sbernini et al., 2018

Swangnetr \& Kaber, 2013

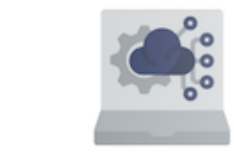

Behaviour \& Information

Technology

Waqar et al., 2019

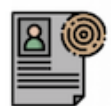

Proceedings of the International Symposium on Human Factors and Ergonomics in Health Care

Patterson et al., 2019

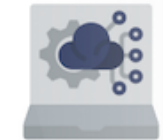

Ergonomics in Design

Gilbank et al., 2020
Table 1 shows the following dimensions: (1) objective of the study; (2) overall methods used, including the ethnographic/quantitative analysis methods adopted, and the type of data ("Methods and Data" column); (3) study participants (user of the AI system); and (4) primary outcome/findings of the study. Most studies involved human participants such as clinicians and patients $(n=33)$ as shown in the "Study Participants" column in Table 1. However, some studies used data from online sources such as Reddit, Twitter, and clinical databases. Approximately 26 studies conducted surveys and interviews to gain insight from study participants, as shown in the "Methods and Data" column. Some studies emphasized algorithms to analyze video, text, and sensor data. Overall, we observed that most studies evaluated AI from the user perspective and others leveraged AI to augment user performance. 
Table 1. Evidentiary table of selected publications, summarizing their objectives, methods, participants, and outcomes (N=48).

\begin{tabular}{|c|c|c|}
\hline Study & Objective & Methods and Data \\
\hline $\begin{array}{l}\text { Aldape-Pérez et } \\
\text { al [24] }\end{array}$ & $\begin{array}{l}\text { To promote collaborative learning } \\
\text { among less experienced physicians }\end{array}$ & Mathematical/ numerical data \\
\hline Azari et al [25] & $\begin{array}{l}\text { To predict surgical maneuvers } \\
\text { from a continuous video record of } \\
\text { surgical benchtop simulations }\end{array}$ & Mathematical/video data \\
\hline $\begin{array}{l}\text { Balani and De } \\
\text { Choudhury [26] }\end{array}$ & $\begin{array}{l}\text { To detect levels of self-disclosure } \\
\text { manifested in posts shared on dif- } \\
\text { ferent mental health forums on } \\
\text { Reddit }\end{array}$ & Mathematical/text data \\
\hline Cai et al [27] & $\begin{array}{l}\text { To identify the needs of patholo- } \\
\text { gists when searching for similar } \\
\text { images, retrieved using a deep- } \\
\text { learning algorithm }\end{array}$ & $\begin{array}{l}\text { Survey study: Mayer's trust } \\
\text { model, NASA-TLX, ques- } \\
\text { tions for mental support for } \\
\text { decision-making, diagnostic } \\
\text { utility, workload, future use, } \\
\text { and preference }\end{array}$ \\
\hline
\end{tabular}

Cvetković and To analyze the influence of age, Interview study using the

Cvetković [28] occupation, education, marital sta-

Ding et al [29] To learn about one's health in ev-

Erebak and To study human-robot interaction Turgut [30] in elder care facilities

Gao et al [34] To detect motor impairment in

Hawkins et al To measure the patient-perceived [35] quality of care in US hospitals

Hu et al [36] To detect lower back pain from

Jin et al [37] To identify, extract, and minimize

Kandaswamy et To predict the accuracy of an order al [38] placed in the EHR ${ }^{\mathrm{b}}$ by emergency

Komogortsev To detect mild traumatic brain in- Mathematical/video data and Holland jury (mTBI) via the application of [39] eye movement biometrics

Krause et al [40] tus, and economic condition on depression in breast cancer patients eryday settings with the help of face-reading technology Parkinson disease via implicitly sensing and analyzing users' everyday interactions with their smartphones body balance and sway performance medical error factors in the medication administration process medicine physicians

Beck Depression Inventory guide

Interview study: specific questions about time and location of usage, users' perceptions and interpretations of the results, and intentions to use it in the future

Survey study: Godspeed anthropomorphism scale, trust checklist [31], scales from [32], and automated functions of [33].

Mathematical; sensor data

Survey study; hospitals were asked to provide feedback regarding their use of Twitter for patient relations

Mathematical; sensor data

Mathematical/text data

Mathematical/text and numer- 53 clinicians ical data

To support the development of understandable predictive models

10 users

NA (Tweets) pants hospitals) pants
Study partici- Immediate outcome observed

pants

$\mathrm{NA}^{\mathrm{a}}$ (online database)

37 surgeons from 7248 users) uals to express or engage in greater selfdisclosure

12 pathologists Users indicated having greater trust in SMILY; it offered better mental support, and providers were more likely to use it in clinical practice

84 patients

Patient age and occupation had the most substantial influence on depression in breast cancer patients

Technology acceptance was hindered due to low technical literacy, low trust, lack of adaptability, infeasible advice, and usability issues

102 caregivers No influence of anthropomorphism was detected on trust in robots; providers who trusted robots had more intention to work with them and preferred a higher automation level

Parkinson disease was detected with significantly higher accuracy when compared to a clinical reference

Patients use Twitter to provide input on the quality of hospital care they receive; almost half of the sentiment toward hospitals was, on average, favorable

44 patients and healthy partici-

The machine-learning model was successful in identifying patients with back pain and responsible factors

NA (data from 4 The proposed machine-learning model identified 12 potential error factors

Machine-learning algorithms identified error rates in imaging, lab, and medication orders

32 patients and healthy partici-

Mathematical/ numerical data 5 data scientists data scientists to interpret predictive models clinically 


\begin{tabular}{ll}
\hline Study & Objective \\
\hline $\begin{array}{l}\text { Ladstatter et al } \\
\text { [41] }\end{array}$ & $\begin{array}{l}\text { To measure the feasibility of artifi- } \\
\text { cial neural networks in analyzing } \\
\text { nurses' burnout process }\end{array}$ \\
$\begin{array}{ll}\text { Ladstatter et al } \\
\text { [42] }\end{array}$ & $\begin{array}{l}\text { To assess whether artificial neural } \\
\text { networks offer better predictive } \\
\text { accuracy in identifying nursing } \\
\text { burnouts than traditional statistical } \\
\text { techniques }\end{array}$ \\
Lee et al [43] & $\begin{array}{l}\text { To determine how wearable de- } \\
\text { vices can help people manage their } \\
\text { itching conditions }\end{array}$ \\
& $\begin{array}{l}\text { To develop a semiautomated ap- } \\
\text { proach to screening cases that de- } \\
\text { scribe hazards associated with } \\
\text { Earella et al } \\
\text { [44] }\end{array}$ \\
$\begin{array}{l}\text { tion-based reporting framework } \\
\text { for patient safety }\end{array}$
\end{tabular}

Mazilu et al To evaluate the impact of a wear[45] able device on gait assist among patients with Parkinson disease

McKnight [46] To analyze patient safety reports.

Moore et al [47] To evaluate natural language processing's performance for extracting abnormal results from free-text mammography and Pap smear reports.

Morrison et al To evaluate the usability and ac[48] ceptability of ASSESS MS.

Muñoz et al To augment the relationship between physical therapists and their patients recovering from a knee injury, using a wearable sensing device

Nobles et al To identify periods of suicidality

Ong et al [51] To automatically categorize clinical incident reports

Park et al [52] To compare discussion topics in publicly accessible online mental health communities for anxiety, depression, and posttraumatic stress disorder

Patterson et al To understand how transparent [53] complex algorithms can be used for predictions, particularly concerning imminent mortality in a hospital environment

Methods and Data Study partici- Immediate outcome observed

pants

Survey study: Nursing

Burnout Scale Short Form

Survey study: Nursing Burnout Scale Short Form

465 nurses

462 nurses

Interview study: user experience and acceptance of the device

Mathematical/text and numer- NA ical data

(n)

Interview study: asking about 18 patients and 5 usability, feasibility, comfort, healthy particiand willingness to use Gait pants Assist.

Mathematical/text data

NA

Mathematical/text data

NA

Interview study: feedback questionnaires, usability scales

51 patients, 6 6 nurses

Interview study to understand 2 physical therahow physical therapists work pists with their patients; user interface design considering usability and comfort

Survey study: evaluating psychology students' communication habits using electronic services

Mathematical/text and numer- NA ical data

Mathematical/text data

NA

Interview study: group discus- 3 researchers sion

26 patients neurologists, and

The artificial neural network identified personality factors as the reason for burnout in Chinese nurses

Artificial neural networks identified a strong personality as one of the leading causes of nursing burnout; it produced a $15 \%$ better result than traditional statistical instruments

40 patients and 2 Machine learning-based itchtector algorithm detected scratch movement more accurately when patients wore it for a longer duration

Naïve Bayes Kernel resulted in the highest classification accuracy; it identified a higher proportion of medication errors and a lower proportion of procedural error than manual screening

$\mathrm{AI}^{\mathrm{c}}$-based Gait Assist was perceived as useful by the patients. Patients reported a reduction in freezing of gait duration and increased confidence during walking

Natural language processing improved the classification of safety reports as Fall and Assault; it also identified unlabeled reports

The performance of natural language processing was comparable to a physician's manual screening

ASSESS MS was perceived as simple, understandable, effective, and efficient; both patients and doctors agreed to use it in the future

Machine learning-based wearable device correctly identified exercises such as leg lifts (100\% accuracy) but also incorrectly identified three nonleg lifts as successfully performed leg lifts (3/18 false positives)

The machine-learning model accurately identified $70 \%$ of suicidality when compared to the default accuracy $(56 \%)$ of a classifier that predicts the most prevalent class

Naïve Bayes and support vector machine correctly identified handover and patient identification incidents with an accuracy of $86.29 \%-91.53 \%$ and $97.98 \%$, respectively

Depression clusters focused on self-expressed contextual aspects of depression, whereas the anxiety disorders and posttraumatic stress disorder clusters addressed more treatment- and medication-related issues

All participants gave contradicting responses 


\begin{tabular}{ll}
\hline Study & Objective \\
\hline Pryor et al [54] & $\begin{array}{l}\text { To analyze the use of a software } \\
\text { medical decision aid by physician } \\
\text { and nonphysicians }\end{array}$ \\
$\begin{array}{l}\text { Putnam et al } \\
\text { T55] }\end{array}$ & $\begin{array}{l}\text { To describe a work-in-progress } \\
\text { that involves therapists who use } \\
\text { motion-based video games for } \\
\text { brain injury rehabilitation }\end{array}$
\end{tabular}

Sbernini et al

[56]

To track surgeons' hand movements during simulated open surgery tasks and to evaluate their manual expertise

Shiner et al [57] To identify inpatient progress notes describing falls

Sonğur and Top To analyze clusters from 12 re[58] gions in Turkey in terms of medical imaging technologies' capacity and use

Swangnetr and To develop an efficient patientKaber [59] emotional classification computational algorithm in interaction with nursing robots in medical care

Wagland et al To analyze the patient experience [60] of care and its effect on health-related quality of life
Wang et al [61] To evaluate a population health intervention to increase anticoagulation use in high-risk patients with atrial fibrillation

Waqar et al [62] To analyze patients' interest in selecting a doctor

Xiao et al [63] To achieve personalized identification of cruciate ligament and soft tissue insertions and, consequently, capture the relationship between the spatial arrangement of soft tissue insertions and patient-specific features extracted from the tibia outlines

Valik et al [64] To develop and validate an automated Sepsis-3-based surveillance system in a nonintensive care unit

Bailey et al [65] To study the implementation of a clinical decision support system (CDSS) for acute kidney injury

Carayon et al To improve the usability of a [66] CDSS
Methods and Data

Observation study; the study indirectly tested the usability and users' trust in the device

Interview study to understand therapists' experiences, opinions, and expectations from motion-based gaming for brain injury rehabilitation

Mathematical/sensor data

18 surgeons

Mathematical/text data

NA

Mathematical/text and numerical data

Survey study: self-assessment manikin questionnaire to measure emotional response to the robot

Survey study regarding treat- NA ment, disease status, physical activity, functional assessment of cancer therapy, and social difficulties inventory

Study partici- Immediate outcome observed

pants

34 clinicians and Physicians did not follow tool recommenda32 nonclinical in- tions, whereas nonphysicians used diagnosdividuals tic support to make medical decisions

11 therapists and Identifying games that were a good match 34 patients for the patient's therapeutic objectives was important; traditional therapists' goals were concentration, sequencing, coordination, agility, partially paralyzed limb utilization reaction time, verbal reasoning, and turntaking

Strategies to reduce sensory glove complexity and increase its comfort did not affect system performance substantially

Natural language processing was highly specific (0.97) but had low sensitivity (0.44) in identifying fall risk compared to manual records review

The study identified inequities in medical imaging technologies according to regions in Turkey and hospital ownership

24 residents

Wavelet-based denoising of galvanic skin response signals led to an increase in the percentage of correct classifications of emotional states, and more transparent relationships among physiological responses and arousal and valence

Nearly half of the total comments analyzed described positive care experiences. Most negative experiences concerned a lack of posttreatment care and insufficient information concerning self-management strategies or treatment side effects

Mathematical/text and numerical data

NA (data from 14 After pharmacist review, only 17\% of algoprimary care clin- rithm-identified patients were considered ics) potentially undertreated

Survey study: systems evaluation from patients' and doctors' perspectives

NA (data from 3 hospitals)

The proposed system solved the problem of doctor recommendations to a good effect when evaluated by domain experts

Mathematical/image data 20 patients The supervised learning and prediction method developed in this study provided accurate information on soft tissue insertion sites using the tibia outlines

The Sepsis- 3 clinical criteria determined by physician review were met in 343 of 1000 instances

Interview and observation

49 clinicians study: organizational work of technology adoption

Hospitals faced difficulties in translating the CDSS's recommendations into routine proactive output

Experimental study: simula- 32 clinicians Emergency physicians faced lower workload and higher satisfaction with the human factors-based CDSS compared to the traditional web-based CDSS 


\begin{tabular}{|c|c|c|c|c|}
\hline Study & Objective & Methods and Data & $\begin{array}{l}\text { Study partici- } \\
\text { pants }\end{array}$ & Immediate outcome observed \\
\hline $\begin{array}{l}\text { Parekh et al } \\
\text { [67] }\end{array}$ & $\begin{array}{l}\text { To develop and validate a risk } \\
\text { prediction tool for medication-re- } \\
\text { lated harm in older adults }\end{array}$ & Mathematical/numerical data & $\begin{array}{l}1280 \text { elderly pa- } \\
\text { tients }\end{array}$ & $\begin{array}{l}\text { The tool used eight variables (age, gender, } \\
\text { antiplatelet drug, sodium level, antidiabetic } \\
\text { drug, past adverse drug reaction, number of } \\
\text { medicines, living alone) to predict harm } \\
\text { with a C-statistic of } 0.69\end{array}$ \\
\hline
\end{tabular}

Gilbank et al To understand the needs of the us[68] er and design requirements for a risk prediction tool
Survey and interview study: informal, semistructured meetings
Miller et al [69] To understand the usability, acceptability, and utility of AI-based symptom assessment and advice technology

ter Stal et al [70]

Gabrielli et al [72]

Liang et al [73] To develop a smartphone camera for self-diagnosing oral health

Chatterjee et al To access the feasibility of a mo[74] bile sensor-based system that can measure the severity of pulmonary obstruction

Beede et al [75] To evaluate a deep learning-based eye-screening system from a human-centered perspective
Survey study to measure ease 523 patients of use

Interview study: Acosta and 20 patients Ward Scale [71]

Experimental, participatory design, and survey study to measure satisfaction

Interview Study to measure usability (NASA-TLX)

Mathematical/numerical data

91 patients, 40 healthy participants

Observation and interview study: unstructured
15 stakeholders from hospitals, academia, industry, and nonprofit organizations
Nine physicians emphasized the need for a prerequisite for trusting the tool. Many participants preferred the technology to have roles complementary to their expertise rather than to perform tasks the physicians had been trained for. Having a tailored recommendation for a local context was deemed critical

425 patients reported that using the Ada symptom checker would not have made a difference in their care-seeking behavior. Most patients found the system easy to use and would recommend it to others

The older male conversational agent was perceived as more authoritative than the young female agent $(P=.03)$. Participants did not see an added value of the agent to the health app

20 children Sixteen children found the chatbot useful and 19 found it easy to use

500 volunteers Two experts agreed that OralCam could give acceptable results. The app also increased oral health knowledge among users

Most patients liked using a smartphone as the assessment tool; they found it comfortable (mean rating 4.63 out of 5 with $\sigma=0.73$ )

13 clinicians, 50 Nurses faced challenges using the deeppatients learning system within clinical care as it would add to their workload. Low image quality and internet speed hindered the performance of the AI system

${ }^{\mathrm{a}} \mathrm{NA}$ : not applicable; these studies have only used data for their respective analyses without involving any human participant (user).

${ }^{b}$ EHR: electronic health record.

${ }^{\mathrm{c}} \mathrm{AI}$ : artificial intelligence.

We observed various algorithms in the final selection, with machine learning being the most common $(n=18)$. Some studies also compared different algorithms based on analytical performance. However, few studies $(n=5$ against clinical/baseline standards, $\mathrm{n}=5$ against clinicians) compared their AI models against a standard measure.

Table 2 summarizes the studies that used machine-learning algorithms. These studies emphasized algorithm development without considering human factors in substantial depth. In other

words, the technological focus of many studies is currently on human-AI collaboration in health care while neglecting real-life clinical evaluation. Discussing studies that primarily focused on analytical performance is beyond the scope of this review. The general flaws and trends of such studies have been addressed in our prior work [7].

Overall, our review indicates that the dimensions of usability, user's perception, workload, and trust in AI have been the most common interest of research in this field. 
Table 2. Artificial intelligence (AI) studies that primarily focused on machine learning (ML) algorithm development $(n=18)$.

\begin{tabular}{|c|c|c|c|c|c|c|}
\hline \multirow[t]{2}{*}{ Reference } & \multirow[t]{2}{*}{$\begin{array}{l}\mathrm{AI} / \mathrm{ML} \text { recommended by } \\
\text { the study }\end{array}$} & \multirow[t]{2}{*}{ Other $\mathrm{AI} / \mathrm{ML} /$ non-AI used in the study } & \multicolumn{4}{|c|}{$\begin{array}{l}\text { Proposed AI model(s) for comparison } \\
\text { (1=compared; } 0=\text { not compared) }\end{array}$} \\
\hline & & & $\begin{array}{l}\text { Other AI } \\
\text { systems }\end{array}$ & $\begin{array}{l}\text { Existing } \\
\text { system } \\
(\text { not } \mathrm{AI})\end{array}$ & $\begin{array}{l}\text { Clinical or } \\
\text { gold stan- } \\
\text { dard }\end{array}$ & $\begin{array}{l}\text { Clini- } \\
\text { cians or } \\
\text { user }\end{array}$ \\
\hline Aldape-Pérez et al [24] & Delta Associative Memory & $\begin{array}{l}\text { AdaBoostM1; bagging; Bayes Net; Dagging; } \\
\text { decision table naïve approach; functional tree; } \\
\text { logistic model trees; logistic regression; naïve } \\
\text { Bayes; random committee; random forest } \\
\text { random subspace; Gaussian radial basis } \\
\text { function network; rotation forest; simple lo- } \\
\text { gistic; support vector machine }\end{array}$ & 1 & 0 & 0 & 0 \\
\hline Azari et al [25] & $\begin{array}{l}\text { Random forest and hidden } \\
\text { Markov model }\end{array}$ & Not applicable & 1 & 1 & 1 & 0 \\
\hline $\begin{array}{l}\text { Balani and De Choud- } \\
\text { hury [26] }\end{array}$ & Perceptron & $\begin{array}{l}\text { Naïve Bayes; k-nearest neighbor; decision } \\
\text { tree }\end{array}$ & 1 & 0 & 0 & 0 \\
\hline $\begin{array}{l}\text { Cvetković and } \\
\text { Cvetković [28] }\end{array}$ & $\begin{array}{l}\text { Neural network and fuzzy } \\
\text { logic }\end{array}$ & Not applicable & 0 & 0 & 0 & 0 \\
\hline Gao et al [34] & AdaBoost & $\begin{array}{l}\text { k-nearest neighbor, support vector machine, } \\
\text { decision tree, random forest, naïve Bayes }\end{array}$ & 1 & 1 & 1 & 0 \\
\hline Hu et al [36] & Deep neural network & Deep neural network with different inputs & 1 & 0 & 0 & 0 \\
\hline Kandaswamy et al [38] & Random forest & $\begin{array}{l}\text { Naïve Bayes; logistic regression; support } \\
\text { vector machine }\end{array}$ & 1 & 0 & 0 & 0 \\
\hline $\begin{array}{l}\text { Komogortsev and Hol- } \\
\text { land [39] }\end{array}$ & $\begin{array}{l}\text { Supervised support vector } \\
\text { machine }\end{array}$ & $\begin{array}{l}\text { Unsupervised support vector machine and } \\
\text { unsupervised heuristic algorithm developed } \\
\text { by the authors }\end{array}$ & 1 & 0 & 0 & 0 \\
\hline Marella et al [44] & Naïve Bayes kernel & $\begin{array}{l}\text { Naïve Bayes; k-nearest neighbor; rule induc- } \\
\text { tion }\end{array}$ & 1 & 0 & 0 & 1 \\
\hline Nobles et al [50] & Deep neural network & Support vector machine & 1 & 0 & 0 & 0 \\
\hline Ong et al [51] & $\begin{array}{l}\text { Naïve Bayes; support vec- } \\
\text { tor machine with radial- } \\
\text { bias function }\end{array}$ & Support vector machine with a linear function & 1 & 1 & 1 & 1 \\
\hline Shiner et al [57] & $\begin{array}{l}\text { Natural language process- } \\
\text { ing }\end{array}$ & $\begin{array}{l}\text { Incident reporting system; manual record re- } \\
\text { view }\end{array}$ & 1 & 1 & 1 & 1 \\
\hline Wagland et al [60] & $\begin{array}{l}\text { Did not recommend any } \\
\text { particular algorithm }\end{array}$ & $\begin{array}{l}\text { Support vector machine; random forest; deci- } \\
\text { sion trees; generalized linear models network; } \\
\text { bagging; max-entropy; logi-boost }\end{array}$ & 1 & 0 & 0 & 0 \\
\hline Waqar et al [62] & $\begin{array}{l}\text { Hybrid algorithm devel- } \\
\text { oped by the authors }\end{array}$ & Not applicable & 0 & 0 & 0 & 0 \\
\hline Xiao et al [63] & $\begin{array}{l}\text { The authors developed a } \\
\text { new algorithm }\end{array}$ & $\begin{array}{l}\text { Linear regression with regularization; LAS- } \\
\mathrm{SO}^{\mathrm{a}} ; \mathrm{k} \text {-nearest neighbor; population mean }\end{array}$ & 1 & 0 & 0 & 0 \\
\hline Valik et al [64] & $\begin{array}{l}\text { The authors developed a } \\
\text { new algorithm }\end{array}$ & Not applicable & 0 & 0 & 1 & 1 \\
\hline Parekh et al [67] & $\begin{array}{l}\text { The authors developed an } \\
\text { algorithm based on multi- } \\
\text { variable logistic regression }\end{array}$ & Not applicable & 0 & 1 & 0 & 0 \\
\hline Chatterjee et al [74] & Gradient boosted tree & Random forest, adaptive boosting & 0 & 0 & 0 & 1 \\
\hline
\end{tabular}

${ }^{\mathrm{a}}$ LASSO: least absolute shrinkage and selection operator.

\section{Perception, Usability, Workload, and Trust}

\section{Perception}

The perception of users was analyzed by several studies to adequately assess the quality of the proposed AI-based recommender system. Some studies incorporated perceptions of both patients and doctors [62,73] in developing their AI systems. Another study interviewed providers (therapists) about their experiences, opinions, expectations, and perceptions of a motion-based game for brain injury rehabilitation to guide the 
design of the proposed AI-based recommender system, which was a case-based reasoning (CBR) system [55]. The AI system ASSESS MS was also developed and evaluated based on users' perceptions [48]. Studies included in our review that developed AI-based apps [27,29], AI robots [30], and wearable AI devices such as Gait Assist [45] and Itchtector [43] also accounted for users' perceptions. From a psychological perspective, emotions might facilitate perception [76]. One study in our review measured users' perception of an AI-based conversational agent [70], and another study developed an AI algorithm for real-time detection of patient emotional states and behavior adaptation to encourage positive health care experiences [59].

\section{Usability}

Some studies in our review performed usability testing of AI systems. For example, one study used AI to develop an adaptable CBR to help therapists ensure proper usability and functioning of CBR [55]. Guided by users' needs, one study [27] developed an AI application (SMILY) to ensure good usability. Users found the clinical information to have higher diagnostic utility while using SMILY (mean 4.7) than while using the conventional interface (mean 3.7). They also experienced less effort (mean 2.8) and expressed higher trust (mean 6) in SMILY than with the conventional interface (mean $4.7 ; P=.01$ ), as well as higher benevolence (mean 5.8 vs 2.6; $P<.001$ ). Another study included in our review noted the literacy gap as a significant hurdle in the usability of an AI-based face-reading app, and identified the impact of adaptability and cultural sensitivity as a limiting factor for usability [29]. Another study codesigned an AI chatbot with 20 students and performed a formative evaluation to better understand their experience of using the tool [72]. Two recent studies measured the perceived usability of AI-based decision-making tools: Ada, an AI tool that helps patients navigate the right type of care [69], and PE-Dx CDS, a tool for diagnosing pulmonary embolism [66]. However, in another study, the researchers primarily focused on developing the algorithm for assessing the severity of pulmonary obstruction and obtained users' feedback on the end product [74]. Poor usability often leads to an increased workload, particularly when the user (provider or patient) is not trained in using the AI system, device, or app.

\section{Workload}

Caregivers are subject to workplace stress and cognitive workload, mostly due to the complexities and uncertainty of patient health and related treatment [77-79], and AI promises to minimize the health care workload through the automation of various levels. Nevertheless, if an AI system or program is poorly designed, the workload may possibly be elevated. Two studies in our review used a radial basis function network to assess burnout among nurses, and consequently captured the nonlinear relationship of the burnout process with the workload, work experience, conflictive interaction, role ambiguity, and other stressors [41,42]. The demand-control theory of work stress implies that workload abnormalities and job intensity can aggravate user fatigue by excessive workloads and trigger anxiety [80]. According to Maslach and Leiter [81], a mismatch between one's skill sets (ability to perform a task) and responsibility (skills required to complete a task) intensifies users' workload. Three studies in our review were invested in minimizing users' workload by assessing the usability of AI systems such as ASSESS MS [48], Gait Assist [45], and SMILY [27].

\section{Trust}

Trust shapes clinicians' and patients' use, adoption, and acceptance of AI [6]. Trust is a psychological phenomenon that supports the inconsistency between the known (clinicians' awareness, patient experience) and the unknown (deep-learning algorithms). Three studies included in our review measured user trust in health care AI systems. One study reported that the anthropomorphism of AI-based care robots has no influence on providers' trust but was significantly related to the level of automation and intention to work with the robot [30]. This study proposed that providers who trusted robots more intended to work with them and preferred a higher automation level [30]. A recent perspective discusses the risk of overreliance or maximum trust in AI (automation) and instead suggests optimal trust between the user and AI system [6]. Besides experience, expertise, and prior knowledge, the performance of the AI technology also determines users' trust. A study included in our review, using a poststudy questionnaire, found that doctors (pathologists) expressed higher trust in SMILY, an AI-based application, due to its better performance, interface, and higher benevolence compared with the conventional app [27]. By contrast, another study reported lower trust of experienced physicians in an AI-based recommendation tool due to its inefficient performance [54]. Based on patient data, expert physicians were able to identify the alternative and better explanation for patient health compared to the AI-based tool [54]. A recent study identified the impact of the AI interface on user's trust [68]. Physicians in this study considered AI's transparency and performance as facilitators of engendering trust.

\section{User-Centered Design}

A user-centric design requires multidisciplinary cooperation between HFE experts, technologists, and end users. The inadequacy of a user-centered design also hinders user perception, usability, and trust, and increases the possibility of errors. The majority of the health care AI literature focuses on quantitative constraints, including performance metrics and precision, and is less focused on the user-centric development of AI technologies. Due to the lack of standard guidelines [7,16], not much research has invested in incorporating a user-centered design in AI-based technologies within the health care industry. In this review, we identified studies that performed experiments involving clinicians and patients, and consecutively evaluated their AI system's (eg, app, wearable device) interface [27], applicability [27,29], and appearance (anthropomorphism) [30] to ensure user-centeredness. Other studies $[43,45,48,49,55,62]$ also addressed user requirements such as wearability and privacy concerns. A recent study further acknowledged the importance of a user-centered clinical field study, and identified external factors such as low lighting, expensive image annotation, and internet speed that can deter the effectiveness of AI systems for diagnosing diabetic retinopathy [75]. 


\section{Discussion}

\section{Main Findings}

Research concerning AI in health care has shown promise for augmenting the quality of health care. However, there is a need for more theoretical advances and interventions that cover all levels and operations across the health care system. We need a systematic approach to safely and effectively bring AI into use, providing human factors, user-centered design, and delivery and implementation science. Many current AI models focus on engineering technology (informatics concepts) and do not sufficiently discuss the relevance of HFE in health care [82]. In this review, we explored and portrayed the involvement of HFE journals and conferences in health care AI research. We identified 48 studies, trending as more publications in recent years, which shows increased attention of the HFE community in this field.

Although advancement and focus have been made in the use of machine learning/AI to develop prediction and classification models, little research has been devoted to real-world translations with a user-centered design approach. To determine the diverse relationships between individuals and technology within a work environment, it is necessary to provide a better explanation as to how AI can be part of the overall health care system through a variety of HFE methods such as the Systems Engineering Initiative for Patient Safety (SEIPS) [83]. The SEIPS provides a framework that helps in comprehending the work system (people, tools and technologies, tasks, working environment, and organization), process (clinical process and process assisting the same), and outcomes (patient outcome, organizational outcome) in the health care domain [83]. This framework also helps to assess and understand the complex interaction between elements of the work system, and shows the impact of any technology-based intervention on the overall system [83].

This review also highlights the need for a systematic approach that evaluates AI's impact (effectiveness) on patient care based on its computational capabilities and compatibility with clinical workflow and usability. Although some studies have acknowledged AI's challenges from both humans factors (biases and usability) [84] and technical (quality of training data and standardization of AI) [7] standpoints, less emphasis has been given so far to the impact of AI integration into clinical processes [16] and services as well as to the user-centered design of AI systems for better human-AI interaction [84,85]. At this stage, where human beings and AI come together, challenges to human factors will likely arise.

\section{Next Steps}

The next push for researchers should be to move AI research beyond solely model development into sociotechnical systems research and effectively use human factors principles. HFE researchers should consider users' needs, capabilities, and interactions with other elements of the work system to ensure the positive impact of AI in transforming health care. Clinical systems are not inherently equivalent to predictable mechanical systems and need a systematic approach. One of the pivotal myths of automation is the assumption that AI can replace clinicians [33]. In fact, the use of AI can shape the activities and duties of clinicians, and might help them in their decision-making. In the domain of medical imaging, AI has shown great promise and is increasing rapidly. For instance, on January 18, 2021, an image analysis platform named AI Metrics received US Food and Drug Administration (FDA) 510(k) clearance [86]. Likewise, in the last 5 years, approximately 222 AI-based medical devices have been approved in the United States [87]. As AI continuous to grow, the associated risks also increase. Many health care AI systems are poorly designed and not evaluated thoroughly [14], and have neglected clinicians' limited absorptive and cognitive capacities and their ability to use AI in clinical settings under a high cognitive workload [88-90]. Incorrect usage or misinterpretation of AI, similar to that of EHRs [91], may also result in patient harm. Therefore, more HFE research should focus on cognitive factors (biases, perceptions, trust), usability, situation awareness, and methodological aspects of AI systems.

\section{Usability}

A user-centered design is essential for health care technologies, where the user is centrally involved in all phases of the design process [92]. However, when the user environment and activities are varied, designing standardized protocols for health care devices and software is complicated. As stated in this study, the problem further increases due to the heterogeneity of applications and AI variants. The human-computer interaction community has developed different user-centered design techniques. However, these methods are often underused by software development teams and organizations [93].

Usually, AI algorithms are complex, opaque, and thus difficult to understand. Therefore, it might be difficult for clinicians/end users to understand and interpret AI outcomes effectively without adequate instruction. Cognitive ergonomics is a fundamental principle dealing with usability issues [94]. Necessary procedural information stored in long-term memory is required to use a technical device [95]. Kieras and Polson [95] suggested the cognitive complexity theory (CCT) explicitly addressing the cognitive complexity of the user-to-device/interface interaction by explaining the user's goals on the one hand and the computer system reaction on the other hand using production rules. The laws of production can be viewed as a series of rules in the form of IF conditions (display status) and THEN actions (input or action taken by the user). According to CCT, cognitive complexity is defined as the number of production rules segregated and learned in a specific action sequence. The definition of cognitive complexity in an AI-based health app can be as helpful as the definition of production rules (ie, the specification of what the system says and how users react) and factors that may contribute concurrently to the app's complexity (ie, interface, menu structure, the language of communication, transparency of functions' naming). It is, however, debatable whether the mere counting of production rules will reasonably assess the troubles perceived by users, considering that various factors contribute equitably to cognitive complexity. Cognitive computing systems [96], which are computing systems that can incorporate human-like cognitive abilities, can also augment and safeguard health care AI by making AI adaptive (learning from a changing 
environment, changing patient health, changing clinician's requirements), interactive (easier human-AI interaction, better usability, easy to understand), iterative and stateful (narrowing down on the problem, considering past decisions/consequence while making current recommendations/tasks), and contextual (consider contextual elements) [96].

Moreover, challenges and hardships perceived by users might be a function of several factors not limited to the user's experience, knowledge, intention of use, and working environment [97]. Therefore, an adaptable usability scale that encompasses the complexity of AI and the common usability factors applicable to that particular system or software should be created by HFE researchers. Perception of an AI system or its perceived ease of use can potentially be a function of users' cognitive and physical abilities. Additionally, the obvious question is, where should user-centered design techniques and knowledge be considered in the life cycle of AI's development?

\section{Trust and Biases}

Human factors research on "automation surprises" primarily began with large-scale industrialization that involved autonomous technologies $[84,98,99]$. The automation surprise arises when an automated machine acts counterintuitively [100]. In health care, automation surprises might lead to confusion, higher workload, distrust, and inefficient operations [101]. In the health care environment, inadequate mental models and insufficient information about AI-based technology might lead to automation surprises and negatively influence trust [6]. Trust can also be hindered if an automated system tends to deter clinicians' performance [6]. Research evaluating the performance of radiologists observed their deterring performance when aided by a decision support system [102]. Therefore, more HFE studies are needed that explore the factors and design requirements influencing users' and clinicians' optimal trust in AI. Future studies should also focus on patient trust in AI-generated recommendations.

When automated diagnostic systems are used in real-life clinics, they most likely are in the form of assistant or recommender systems where the AI system provides information to clinicians or patients as a second opinion. However, if the suggestions made by AI are entirely data-driven without accounting for the user's opinion, as is the case for current designs, users could be biased toward or against the suggestion of the AI system [103] Optimizing such user-AI trust interplay remains a challenge that HFE experts should consider as their future endeavor.

It should be noted that advocating for trust in automation for a prolonged time can also promote automation bias. Aviation studies have recorded instances of automation biases where pilots could not track vital flight indicators in the event of failure due to overreliance on the autopilot [104,105]. A review of automation bias focusing on the health care literature noted that the complexity of any assignment and the workload increased the likelihood of excessive reliance on automation [106], which can be detrimental to patient safety. Human factors such as cognitive ergonomics and a user-centered design should be utilized efficiently to minimize the health care AI system's automation biases.

\section{Situation Awareness}

Situation awareness is defined as "the perception of the elements in the environment within a volume of time and space, the comprehension of their meaning and the projection of their status in the near future" [107]. "Good" situation awareness is a prerequisite to better performance [84,107]. There might be an ongoing discussion around maximum versus optimum situation awareness. It is critical to understand that the optimum situation awareness is not necessarily the maximum situation awareness [108]. Maximizing the user's situation awareness does not necessarily yield the best outcome (decisions from a human-AI collaboration) [108]. For example, concentrating on irrelevant details such as radio commercials, talking passengers, or the colors of other cars while driving may unnecessarily consume the driver's working memory, increase the workload, or even act as a distraction [109].

Similarly, in a clinical setting, it is better to achieve optimal situation awareness rather than maximum situation awareness. Many studies have shown the deterring impact of excessive and unnecessary information on clinical work [110,111]. For example, false or irrelevant clinical alarms may increase the tension of nurses and even distract them. Performing critical health care tasks (such as administering narcotic medication, watching telemetry monitors) demands optimal situation awareness [112]; however, unnecessary or irrelevant situation awareness can disturb clinicians' attention and working memory. Exploration of AI's influence on clinicians' situation awareness has not been studied extensively. More HFE-based research is needed to further explain the concept of optimal situation awareness in AI design. Both humans and AI each have skepticism regarding the information generated in their surroundings and extract the data that seem vital for clinical decision-making.

\section{Ecological Validation}

The development, evaluation, and integration of sophisticated AI-based medical devices can be a challenging process requiring multidisciplinary engagement. It may enable a personalized approach to patient care through improved diagnosis and prognosis of individual responses to therapies, along with efficient comprehension of health databases. This solution has the power to reinvigorate clinical practices. Although the advent of personalized patient treatment is provocative, there is a need to evaluate the true potential of AI. The performance of AI depends on the quantity and quality of data available for training, as acknowledged in recent review papers $[7,16]$. Perhaps one of the most essential facts from the HFE viewpoint is that poor usability causes improper, inaccurate, and inefficient use [113]. Although the importance of usability testing and a user-centered design for medical devices has been substantially stated by the FDA [114] and other HFE experts, both regulatory guidelines and evaluation approaches fail to reflect the challenges faced by clinicians during their routine clinical activity [115]. In other words, most studies identified in our review were performed in a controlled environment, therefore lacking ecological validity. This finding is consistent with most other research in the field of AI and health care. Recent systematic reviews [7,16,116] analyzing AI's role and performance in health care 
acknowledged that AI systems or models were often evaluated under unrealistic conditions that had minimal relevance to routine clinical practice.

Users under stress and discomfort might not be efficient in utilizing AI devices with poor usability. Unlike research or controlled settings, a clinical setting demands multitasking where clinicians (nurses) have to attend to several patients with different ailments. They also have to write clinical notes, monitor health fluctuations, administer critical medications, float to different departments during shortage of staff, educate new nurses, and respond to protocols in cases of emergency. Under such a working environment and cognitive workload, interpreting or learning to use an AI system that is not designed appropriately can be challenging and risky. Therefore, an AI system that perfectly qualifies usability tests in a research setting may fail in a clinical environment. Given these limitations, the few studies in our review that compared their AI model with clinical standards (see Table 2) are less relevant because the comparisons against clinical standards were made in an (ideal) controlled environment or without providing contextual information about the patient and the environment [117]. Moreover, the work system elements also differ substantially from an intensive care unit to an outpatient clinic. Therefore, AI-based medical systems must be evaluated in their respective clinical environment to ensure safer deployment.

\section{Limitations of the Review}

This review does not include the complete available literature but was constrained within the selected journals and conferences. Studies investigating human-AI interactions in a health care context or leveraging HFE principles to evaluate health care AI systems published in non-HFE venues such as pure medical or informatics journals have not been included in this review. Notwithstanding these constraints, our analysis identified possible research gaps in the health disciplines that could, if addressed, help mobilize and integrate AI more efficiently and safely.

\section{Conclusion}

HFE researchers should actively design and implement AI, and perform dynamical assessments of AI systems' effects on interaction, workflow, and patient outcomes. An AI system is part of a greater sociotechnical system. Investigators with HFE expertise are essential when defining the dynamic interaction of AI within each element, process, and result of the work system. This means that we ought to adapt our strategy to the situations and contexts in the field; simultaneously, we must also find practical ways of generating more compelling evidence for our research.

\section{Acknowledgments}

We thank Mr. Nikhil Shetty and Ms. Safa Elkefi, graduate students at Stevens Institute of Technology, for assisting us with the preliminary literature search. This research received no specific grant from any funding agency in public, commercial, or not-for-profit sectors.

\section{Authors' Contributions}

OA conceived and designed the study; developed the protocol; participated in data collection (literature review), analysis, and interpretation; drafted and revised the manuscript; and approved the final version for submission. AC designed the study; developed the review protocol and graphical illustrations; participated in the literature review, analysis, and interpretation; drafted and revised the manuscript; and approved the final version for submission.

\section{Conflicts of Interest}

None declared.

\section{Multimedia Appendix 1}

Journal and conference proceedings list for the review.

[DOCX File, 19 KB-Multimedia Appendix 1]

\section{References}

1. Wang P. On defining artificial intelligence. J Artif Gen Intell 2019;10(2):1-37. [doi: 10.2478/jagi-2019-0002]

2. Leão C, Gonçalves P, Cepeda T, Botelho L, Silva C. Study of the knowledge and impact of artificial intelligence on an academic community. 2018 Sep 25 Presented at: International Conference on Intelligent Systems (IS); 2018 ; Funchal p. 891-895. [doi: 10.1109/is.2018.8710477]

3. McCarthy J, Hayes P. Some philosophical problems from the standpoint of artificial intelligence. In: Meltzer B, Michie D, editors. Machine Intelligence 4. Edinburgh, UK: Edinburgh University Press; 1981:463-502.

4. Pedregosa F, Varoquaux G, Gramfort A, Michel V, Thirion B, Grisel O, et al. Scikit-learn: machine learning in Python (decision trees). J Mach Learn Res 2011;12(1):2825-2830.

5. Helm JM, Swiergosz AM, Haeberle HS, Karnuta JM, Schaffer JL, Krebs VE, et al. Machine learning and artificial intelligence: definitions, applications, and future directions. Curr Rev Musculoskelet Med 2020 Feb;13(1):69-76 [FREE Full text] [doi: 10.1007/s12178-020-09600-8] [Medline: 31983042] 
6. Asan O, Bayrak AE, Choudhury A. Artificial intelligence and human trust in healthcare: focus on clinicians. J Med Internet Res 2020 Jun 19;22(6):e15154 [FREE Full text] [doi: 10.2196/15154] [Medline: 32558657]

7. Choudhury A, Asan O. Role of artificial intelligence in patient safety outcomes: systematic literature review. JMIR Med Inform 2020 Jul 24;8(7):e18599 [FREE Full text] [doi: 10.2196/18599] [Medline: 32706688]

8. Ardila D, Kiraly AP, Bharadwaj S, Choi B, Reicher JJ, Peng L, et al. End-to-end lung cancer screening with three-dimensional deep learning on low-dose chest computed tomography. Nat Med 2019 Jun;25(6):954-961. [doi: 10.1038/s41591-019-0447-x] [Medline: 31110349$]$

9. Obermeyer Z, Emanuel EJ. Predicting the future - big data, machine learning, and clinical medicine. N Engl J Med 2016 Sep 29;375(13):1216-1219 [FREE Full text] [doi: 10.1056/NEJMp1606181] [Medline: 27682033]

10. Esteva A, Kuprel B, Novoa RA, Ko J, Swetter SM, Blau HM, et al. Dermatologist-level classification of skin cancer with deep neural networks. Nature 2017 Feb 02;542(7639):115-118. [doi: 10.1038/nature21056] [Medline: 28117445]

11. Lovett L. Google demos its EHR-like clinical documentation tool. Mobi Health News. 2019. URL: https://www. mobihealthnews.com/news/north-america/google-demos-its-ehr-clinical-documentation-tool [accessed 2020-07-17]

12. Kelly CJ, Karthikesalingam A, Suleyman M, Corrado G, King D. Key challenges for delivering clinical impact with artificial intelligence. BMC Med 2019 Oct 29;17(1):195 [FREE Full text] [doi: 10.1186/s12916-019-1426-2] [Medline: 31665002]

13. Mnih V, Kavukcuoglu K, Silver D, Graves A, Antonoglou I, Wierstra D. Playing Atari with deep reinforcement learning. arXiv preprint. 2013. URL: https://arxiv.org/abs/1312.5602 [accessed 2021-06-15]

14. Kleinman Z. Most healthcare apps not up to NHS standards. BBC News. URL: https://www.bbc.com/news/ technology-56083231 [accessed 2021-01-20]

15. Nicholson Price II W. Risks and remedies for artificial intelligence in health care. Brookings. URL: https://www. brookings.edu/research/risks-and-remedies-for-artificial-intelligence-in-health-care/ [accessed 2020-12-25]

16. Choudhury A, Renjilian E, Asan O. Use of machine learning in geriatric clinical care for chronic diseases: a systematic literature review. JAMIA Open 2020 Oct;3(3):459-471 [FREE Full text] [doi: 10.1093/jamiaopen/ooaa034] [Medline: 33215079]

17. Lau N, Hildebrandt M, Althoff T, Boyle LN, Iqbal ST, Lee JD, et al. Human in focus: future research and applications of ubiquitous user monitoring. 2019 Nov 20 Presented at: Proceedings of the Human Factors and Ergonomics Society Annual Meeting. /11/01;63(1); 2019; Philidephia p. 168-172. [doi: 10.1177/1071181319631317]

18. Lau N, Hildebrandt M, Jeon M. Ergonomics in AI: designing and interacting with machine learning and AI. Ergon Des 2020 Jun 05;28(3):3. [doi: 10.1177/1064804620915238]

19. Panch T, Mattie H, Celi LA. The "inconvenient truth" about AI in healthcare. NPJ Digit Med 2019 Aug 16;2(1):77-73. [doi: 10.1038/s41746-019-0155-4] [Medline: 31453372 ]

20. Rajkomar A, Dean J, Kohane I. Machine learning in medicine. N Engl J Med 2019 Apr 04;380(14):1347-1358. [doi: 10.1056/nejmra1814259]

21. Choudhury A, Asan O. Human Factors and Artificial Intelligence Around Healthcare: A Mapping Review Protocol. Open Science Framework. 2020. URL: https://osf.io/qy295/ [accessed 2021-02-15]

22. Grant MJ, Booth A. A typology of reviews: an analysis of 14 review types and associated methodologies. Health Info Libr J 2009 Jun;26(2):91-108. [doi: 10.1111/j.1471-1842.2009.00848.x] [Medline: 19490148]

23. Holden RJ, Cornet VP, Valdez RS. Patient ergonomics: 10-year mapping review of patient-centered human factors. Appl Ergon 2020 Jan;82:102972. [doi: 10.1016/j.apergo.2019.102972] [Medline: 31654954]

24. Aldape-Pérez M, Yáñez-Márquez C, Camacho-Nieto O, López-Yáñez I, Argüelles-Cruz AJ. Collaborative learning based on associative models: Application to pattern classification in medical datasets. Comput Hum Behav 2015 Oct;51:771-779. [doi: 10.1016/j.chb.2014.11.091]

25. Azari DP, Hu YH, Miller BL, Le BV, Radwin RG. Using surgeon hand motions to predict surgical maneuvers. Hum Factors 2019 Dec;61(8):1326-1339. [doi: 10.1177/0018720819838901] [Medline: 31013463 ]

26. Balani S, De Choudhury M. Detecting and characterizing mental health related self-disclosure in social media. 2015 Presented at: Proceedings of the 33rd Annual ACM Conference Extended Abstracts on Human Factors in Computing Systems - CHI EA '15; 2015; Seoul p. 1373-1378. [doi: 10.1145/2702613.2732733]

27. Cai C, Stumpe M, Terry M, Reif E, Hegde N, Hipp J. Human-centered tools for coping with imperfect algorithms during medical decision-making. 2019 Presented at: Proceedings of the CHI Conference on Human Factors in Computing Systems - CHI '19; 2019; Glasgow p. 1-14. [doi: 10.1145/3290605.3300234]

28. Cvetković J, Cvetković M. Investigation of the depression in breast cancer patients by computational intelligence technique. Comput Hum Behav 2017 Mar;68:228-231. [doi: 10.1016/j.chb.2016.11.042]

29. Ding X, Jiang Y, Qin X, Chen Y, Zhang W, Qi L. Reading Face, Reading Health. 2019 Presented at: Proceedings of the CHI Conference on Human Factors in Computing Systems - CHI '19; 2019; Glasgow p. 1-13. [doi: 10.1145/3290605.3300435]

30. Erebak S, Turgut T. Caregivers' attitudes toward potential robot coworkers in elder care. Cogn Tech Work 2018 Jul 24;21(2):327-336. [doi: 10.1007/s10111-018-0512-0]

31. Jian J, Bisantz A, Drury C. Foundations for an empirically determined scale of trust in automated systems. Int J Cogn Ergon 2000 Mar;4(1):53-71. [doi: 10.1207/s15327566ijce0401_04] 
32. Chang M, Cheung W. Determinants of the intention to use Internet/WWW at work: a confirmatory study. Inf Manag 2001 Nov;39(1):1-14. [doi: 10.1016/s0378-7206(01)00075-1]

33. Parasuraman R, Sheridan TB, Wickens CD. A model for types and levels of human interaction with automation. IEEE Trans Syst Man Cybern A Syst Hum 2000 May;30(3):286-297. [doi: 10.1109/3468.844354] [Medline: 11760769]

34. Gao J, Tian F, Fan J, Wang D, Fan X, Zhu Y. Implicit detection of motor impairment in Parkinson's disease from everyday smartphone interactions. 2018 Presented at: CHI Conference on Human Factors in Computing Systems; 2018; Montreal p. 1-6. [doi: 10.1145/3170427.3188502]

35. Hawkins JB, Brownstein JS, Tuli G, Runels T, Broecker K, Nsoesie EO, et al. Measuring patient-perceived quality of care in US hospitals using Twitter. BMJ Qual Saf 2016 Jun;25(6):404-413 [FREE Full text] [doi: 10.1136/bmjqs-2015-004309] [Medline: 26464518]

36. Hu B, Kim C, Ning X, Xu X. Using a deep learning network to recognise low back pain in static standing. Ergonomics 2018 Oct;61(10):1374-1381. [doi: 10.1080/00140139.2018.1481230] [Medline: 29792576]

37. Jin H, Qu Q, Munechika M, Sano M, Kajihara C, Duffy VG, et al. Applying intelligent algorithms to automate the identification of error factors. J Patient Saf 2018 May 03:online ahead of print. [doi: 10.1097/PTS.0000000000000498] [Medline: 29733301]

38. Kandaswamy S, Hettinger AZ, Ratwani RM. What did you order? Developing models to measure the impact of usability on emergency physician accuracy using computerized provider order entry. 2019 Nov 20 Presented at: Human Factors and Ergonomics Society Annual Meeting; 2019; Philidephia p. 713-717. [doi: 10.1177/1071181319631461]

39. Komogortsev O, Holland C. The application of eye movement biometrics in the automated detection of mild traumatic brain injury. 2014 Presented at: Proceedings of the extended abstracts of the 32nd annual ACM conference on Human factors in computing systems - CHI EA '14; 2014; Toronto p. 1711-1716. [doi: 10.1145/2559206.2581150]

40. Krause J, Perer A, Ng K. Interacting with predictions. 2016 Presented at: Proceedings of the CHI Conference on Human Factors in Computing Systems; 2016; Montreal p. 5686-5697. [doi: 10.1145/2858036.2858529]

41. Ladstätter F, Garrosa E, Moreno-Jiménez B, Ponsoda V, Reales Aviles JM, Dai J. Expanding the occupational health methodology: A concatenated artificial neural network approach to model the burnout process in Chinese nurses. Ergonomics 2016;59(2):207-221. [doi: 10.1080/00140139.2015.1061141] [Medline: 26230967]

42. Ladstätter F, Garrosa E, Badea C, Moreno B. Application of artificial neural networks to a study of nursing burnout. Ergonomics 2010 Sep;53(9):1085-1096. [doi: 10.1080/00140139.2010.502251] [Medline: 20737334]

43. Lee J, Cho D, Kim J, Im E, Bak J. Itchtector: A wearable-based mobile system for managing itching conditions. 2017 Presented at: Proceedings of the 2017 CHI Conference on Human Factors in Computing Systems; 2017; Montreal p. 893-905. [doi: 10.1145/3025453.3025569]

44. Marella WM, Sparnon E, Finley E. Screening electronic health record-related patient safety reports using machine learning. J Patient Saf 2017 Mar;13(1):31-36. [doi: 10.1097/PTS.0000000000000104] [Medline: 24721977]

45. Mazilu S, Blanke U, Hardegger M, Tröster G, Gazit E, Hausdorff J. GaitAssist. 2014 Presented at: Proceedings of the 32nd Annual ACM Conference on Human Factors in Computing Systems - CHI '14; 2014; Toronto p. 2531-2540. [doi: 10.1145/2556288.2557278]

46. McKnight SD. Semi-supervised classification of patient safety event reports. J Patient Saf 2012 Jun;8(2):60-64. [doi: 10.1097/PTS.0b013e31824ab987] [Medline: 22543364]

47. Moore CR, Farrag A, Ashkin E. Using natural language processing to extract abnormal results from cancer screening reports. J Patient Saf 2017 Sep;13(3):138-143 [FREE Full text] [doi: 10.1097/PTS.0000000000000127] [Medline: 25025472]

48. Morrison C, D'Souza M, Huckvale K, Dorn JF, Burggraaff J, Kamm CP, et al. Usability and acceptability of ASSESS MS: assessment of motor dysfunction in multiple sclerosis using depth-sensing computer vision. JMIR Hum Factors 2015 Jun 24;2(1):e11 [FREE Full text] [doi: 10.2196/humanfactors.4129] [Medline: 27025782]

49. Muñoz M, Cobos A, Campos A. Low vacuum re-infusion drains after total knee arthroplasty: is there a real benefit? Blood Transfus 2014 Jan;12(Suppl 1):s173-s175. [doi: 10.2450/2013.0236-13] [Medline: 24120601]

50. Nobles A, Glenn J, Kowsari K, Teachman B, Barnes L. Identification of imminent suicide risk among young adults using text messages. 2018 Presented at: SIGCHI Conference on Human Factors in Computing Systems; 2018; San Fransisco. [doi: $10.1145 / 3173574.3173987]$

51. Ong M, Magrabi F, Coiera E. Automated categorisation of clinical incident reports using statistical text classification. Qual Saf Health Care 2010 Dec;19(6):e55. [doi: 10.1136/qshc.2009.036657] [Medline: 20724392]

52. Park A, Conway M, Chen AT. Examining thematic similarity, difference, and membership in three online mental health communities from Reddit: a text mining and visualization approach. Comput Human Behav 2018 Jan;78:98-112 [FREE Full text] [doi: 10.1016/j.chb.2017.09.001] [Medline: 29456286]

53. Patterson ES, Hansen CJ, Allen TT, Yang Q, Moffatt-Bruce SD. Predicting mortality with applied machine learning: Can we get there? Proc Int Symp Hum Factors Ergon Healthc 2019 Sep;8(1):115-119 [FREE Full text] [doi: 10.1177/2327857919081026] [Medline: 33024791]

54. Pryor M, Ebert D, Byrne V, Richardson K, Jones Q, Cole R, et al. Diagnosis behaviors of physicians and non-physicians when supported by an electronic differential diagnosis aid. 2019 Nov 20 Presented at: Proceedings of the Human Factors and Ergonomics Society Annual Meeting. /11/01;63(1); 2019; Philidephia p. 68-72. [doi: 10.1177/1071181319631420] 
55. Putnam C, Cheng J, Rusch D, Berthiaume A, Burke R. Supporting therapists in motion-based gaming for brain injury rehabilitation. 2013 Presented at: CHI '13 Extended Abstracts on Human Factors in Computing Systems; 2013; Paris p. 391. [doi: $10.1145 / 2468356.2468426]$

56. Sbernini L, Quitadamo L, Riillo F, Lorenzo N, Gaspari A, Saggio G. Sensory-glove-based open surgery skill evaluation. IEEE Trans Hum Mach Syst 2018 Apr;48(2):213-218. [doi: 10.1109/thms.2017.2776603]

57. Shiner B, Neily J, Mills PD, Watts BV. Identification of inpatient falls using automated review of text-based medical records. J Patient Saf 2020 Sep;16(3):e174-e178. [doi: 10.1097/PTS.0000000000000275] [Medline: 27331601]

58. Sonğur C, Top M. Regional clustering of medical imaging technologies. Comput Hum Behav 2016 Aug;61:333-343. [doi: 10.1016/j.chb.2016.03.056]

59. Swangnetr M, Kaber D. Emotional state classification in patient-robot interaction using wavelet analysis and statistics-based feature selection. IEEE Trans Hum Mach Syst 2013 Jan;43(1):63-75. [doi: 10.1109/tsmca.2012.2210408]

60. Wagland R, Recio-Saucedo A, Simon M, Bracher M, Hunt K, Foster C, et al. Development and testing of a text-mining approach to analyse patients' comments on their experiences of colorectal cancer care. BMJ Qual Saf 2016 Aug;25(8):604-614. [doi: 10.1136/bmjqs-2015-004063] [Medline: 26512131]

61. Wang SV, Rogers JR, Jin Y, DeiCicchi D, Dejene S, Connors JM, et al. Stepped-wedge randomised trial to evaluate population health intervention designed to increase appropriate anticoagulation in patients with atrial fibrillation. BMJ Qual Saf 2019 Oct;28(10):835-842. [doi: 10.1136/bmjqs-2019-009367] [Medline: $\underline{\text { 31243156] }}$

62. Waqar M, Majeed N, Dawood H, Daud A, Aljohani N. An adaptive doctor-recommender system. Behav Inf Technol 2019:959-973. [doi: 10.1080/0144929x.2019.1625441]

63. Xiao C, Wang S, Zheng L, Zhang X, Chaovalitwongse W. A patient-specific model for predicting tibia soft tissue insertions from bony outlines using a spatial structure supervised learning framework. IEEE Trans Hum Mach Syst 2016 Oct;46(5):638-646. [doi: 10.1109/thms.2016.2545924]

64. Valik JK, Ward L, Tanushi H, Müllersdorf K, Ternhag A, Aufwerber E, et al. Validation of automated sepsis surveillance based on the Sepsis-3 clinical criteria against physician record review in a general hospital population: observational study using electronic health records data. BMJ Qual Saf 2020 Sep 06;29(9):735-745 [FREE Full text] [doi: 10.1136/bmjqs-2019-010123] [Medline: 32029574]

65. Bailey S, Hunt C, Brisley A, Howard S, Sykes L, Blakeman T. Implementation of clinical decision support to manage acute kidney injury in secondary care: an ethnographic study. BMJ Qual Saf 2020 May 03;29(5):382-389 [FREE Full text] [doi: 10.1136/bmjqs-2019-009932] [Medline: 31796574]

66. Carayon P, Hoonakker P, Hundt AS, Salwei M, Wiegmann D, Brown RL, et al. Application of human factors to improve usability of clinical decision support for diagnostic decision-making: a scenario-based simulation study. BMJ Qual Saf 2020 Apr 27;29(4):329-340 [FREE Full text] [doi: 10.1136/bmjqs-2019-009857] [Medline: $\underline{31776197]}$

67. Parekh N, Ali K, Davies JG, Stevenson JM, Banya W, Nyangoma S, et al. Medication-related harm in older adults following hospital discharge: development and validation of a prediction tool. BMJ Qual Saf 2020 Feb 16;29(2):142-153 [FREE Full text] [doi: 10.1136/bmjqs-2019-009587] [Medline: 31527053]

68. Gilbank P, Johnson-Cover K, Truong T. Designing for physician trust: toward a machine learning decision aid for radiation toxicity risk. Ergon Design 2019 Dec 29;28(3):27-35. [doi: 10.1177/1064804619896172]

69. Miller S, Gilbert S, Virani V, Wicks P. Patients' utilization and perception of an artificial intelligence-based symptom assessment and advice technology in a British primary care waiting room: exploratory pilot study. JMIR Hum Factors 2020 Jul 10;7(3):e19713 [FREE Full text] [doi: 10.2196/19713] [Medline: 32540836]

70. Ter Stal S, Broekhuis M, van Velsen L, Hermens H, Tabak M. Embodied conversational agent appearance for health assessment of older adults: explorative study. JMIR Hum Factors 2020 Sep 04;7(3):e19987 [FREE Full text] [doi: 10.2196/19987] [Medline: 32886068 ]

71. Acosta J, Ward N. Achieving rapport with turn-by-turn, user-responsive emotional coloring. Speech Commun 2011 Nov;53(9-10):1137-1148. [doi: 10.1016/j.specom.2010.11.006]

72. Gabrielli S, Rizzi S, Carbone S, Donisi V. A chatbot-based coaching intervention for adolescents to promote life skills: pilot study. JMIR Hum Factors 2020 Feb 14;7(1):e16762 [FREE Full text] [doi: 10.2196/16762] [Medline: 32130128]

73. Liang Y, Fan H, Fang Z, Miao L, Li W, Zhang X. OralCam: enabling self-examination and awareness of oral health using a smartphone camera. USA: Association for Computing Machinery; 2020 Presented at: 2020 CHI Conference on Human Factors in Computing Systems; 2020; Honolulu. [doi: 10.1145/3313831.3376238]

74. Chatterjee S, Rahman M, Ahmed T, Saleheen N, Nemati E, Nathan V. Assessing severity of pulmonary obstruction from respiration phase-based wheeze-sensing using mobile sensors. USA: Association for Computing Machinery; 2020 Presented at: 2020 CHI Conference on Human Factors in Computing Systems; 2020; Honolulu. [doi: 10.1145/3313831.3376444]

75. Beede E, Baylor E, Hersch F, Iurchenko A, Wilcox L, Ruamviboonsuk P. A human-centered evaluation of a deep learning system deployed in clinics for the detection of diabetic retinopathy. USA: Association for Computing Machinery; 2020 Presented at: 2020 CHI Conference on Human Factors in Computing Systems; 2020; Honolulu. [doi: 10.1145/3313831.3376718]

76. Phelps EA, Ling S, Carrasco M. Emotion facilitates perception and potentiates the perceptual benefits of attention. Psychol Sci 2006 Apr;17(4):292-299 [FREE Full text] [doi: 10.1111/j.1467-9280.2006.01701.x] [Medline: 16623685] 
77. Ruotsalainen JH, Verbeek JH, Mariné A, Serra C. Preventing occupational stress in healthcare workers. Cochrane Database Syst Rev 2015 Apr 07(4):CD002892 [FREE Full text] [doi: 10.1002/14651858.CD002892.pub5] [Medline: 25847433]

78. Marine A, Ruotsalainen J, Serra C, Verbeek J. Preventing occupational stress in healthcare workers. Cochrane Database Syst Rev 2006 Oct 18(4):CD002892. [doi: 10.1002/14651858.CD002892.pub2] [Medline: 17054155]

79. McVicar A. Workplace stress in nursing: a literature review. J Adv Nurs 2003 Dec;44(6):633-642. [doi: 10.1046/j.0309-2402.2003.02853.x] [Medline: 14651686 ]

80. Karasek R, Theorell T. Healthy work: stress, productivity, and the reconstruction of working life. New York: Basic Books; Apr 12, 1992.

81. Maslach C, Leiter M. The truth about burnout: How organizations cause personal stress and what to do about it:. Hoboken, NJ: John Wiley \& Sons; 2008.

82. Anderson JE, Ross AJ, Macrae C, Wiig S. Defining adaptive capacity in healthcare: A new framework for researching resilient performance. Appl Ergon 2020 Sep;87:103111. [doi: 10.1016/j.apergo.2020.103111] [Medline: 32310111]

83. Carayon P, Schoofs Hundt A, Karsh B, Gurses AP, Alvarado CJ, Smith M, et al. Work system design for patient safety: the SEIPS model. Qual Saf Health Care 2006 Dec;15(Suppl 1):i50-i58 [FREE Full text] [doi: 10.1136/qshc.2005.015842] [Medline: 17142610 ]

84. Sujan M, Furniss D, Grundy K, Grundy H, Nelson D, Elliott M, et al. Human factors challenges for the safe use of artificial intelligence in patient care. BMJ Health Care Inform 2019 Nov;26(1):e100081 [FREE Full text] [doi:

10.1136/bmjhci-2019-100081] [Medline: 31780459]

85. Felmingham CM, Adler NR, Ge Z, Morton RL, Janda M, Mar VJ. The importance of incorporating human factors in the design and implementation of artificial intelligence for skin cancer diagnosis in the real world. Am J Clin Dermatol 2021 Mar 22;22(2):233-242. [doi: 10.1007/s40257-020-00574-4] [Medline: 33354741]

86. FDA Cleared AI Algorithms. Data Science Institute. URL: https://models.acrdsi.org [accessed 2021-02-15]

87. Muehlematter UJ, Daniore P, Vokinger KN. Approval of artificial intelligence and machine learning-based medical devices in the USA and Europe (2015-20): a comparative analysis. Lancet Digital Health 2021 Mar;3(3):e195-e203. [doi: 10.1016/s2589-7500(20)30292-2]

88. Plsek PE, Greenhalgh T. Complexity science: The challenge of complexity in health care. BMJ 2001 Sep 15;323(7313):625-628 [FREE Full text] [doi: 10.1136/bmj.323.7313.625] [Medline: 11557716]

89. Plsek PE, Wilson T. Complexity, leadership, and management in healthcare organisations. BMJ 2001 Sep 29;323(7315):746-749 [FREE Full text] [doi: 10.1136/bmj.323.7315.746] [Medline: 11576986]

90. Patel VL, Zhang J, Yoskowitz NA, Green R, Sayan OR. Translational cognition for decision support in critical care environments: a review. J Biomed Inform 2008 Jun;41(3):413-431 [FREE Full text] [doi: 10.1016/j.jbi.2008.01.013] [Medline: 18343731 ]

91. Schulte F, Fry E. Death By 1,000 Clicks: Where Electronic Health Records Went Wrong. Fortune. 2019. URL: https://khn. org/news/death-by-a-thousand-clicks/ [accessed 2020-07-09]

92. De Vito Dabbs A, Myers BA, Mc Curry KR, Dunbar-Jacob J, Hawkins RP, Begey A, et al. User-centered design and interactive health technologies for patients. Comput Inform Nurs 2009;27(3):175-183 [FREE Full text] [doi: 10.1097/NCN.0b013e31819f7c7c] [Medline: 19411947]

93. Schnall R, Cho H, Liu J. Health Information Technology Usability Evaluation Scale (Health-ITUES) for usability assessment of mobile health technology: validation study. JMIR Mhealth Uhealth 2018 Jan 05;6(1):e4 [FREE Full text] [doi: 10.2196/mhealth.8851] [Medline: 29305343]

94. Nunes I. Ergonomics and usability: key factors in knowledge society. Enterpr Work Innov Stud 2006:88-94 [FREE Full $\underline{\text { text] }}$

95. Kieras D, Polson PG. An approach to the formal analysis of user complexity. Int J Hum Comput Stud 1999 Aug;51(2):405-434. [doi: 10.1006/ijhc.1983.0317]

96. Schuetz S, Venkatesh V. The rise of human machines: how cognitive computing systems challenge assumptions of user-system interaction. J Assoc Inf Syst 2020:460-482. [doi: 10.17705/1jais.00608]

97. Davis F. User acceptance of information technology: system characteristics, user perceptions and behavioral impacts. Int J Man Machine Stud 1993 Mar;38(3):475-487. [doi: 10.1006/imms.1993.1022]

98. Bainbridge L. Ironies of automation. Analysis, design and evaluation of man-machine systems. 1982 Presented at: Proceedings of IFAC/IFIP/IFORS/IEA Conference; 1982; Baden p. 151-157. [doi: 10.1016/b978-0-08-029348-6.50026-9]

99. Salvendy G. Handbook of human factors and ergonomics. 4th edition. Hoboken, NJ: John Wiley \& Sons; 2012.

100. Sarter N, Woods D, Billings C. Automation surprises. In: Salvendy G, editor. Handbook of human factors and ergonomics. Hoboken, NJ: Wiley; 1997:1926-1943.

101. Ruskin K, Ruskin A, O'Connor M. Automation failures and patient safety. Curr Opin Anaesthesiol 2020 Dec;33(6):788-792. [doi: 10.1097/ACO.0000000000000935] [Medline: 33093302]

102. Alberdi E, Povykalo A, Strigini L, Ayton P. Effects of incorrect computer-aided detection (CAD) output on human decision-making in mammography. Acad Radiol 2004 Aug;11(8):909-918. [doi: 10.1016/j.acra.2004.05.012] [Medline: 15354301] 
103. Tschandl P, Rinner C, Apalla Z, Argenziano G, Codella N, Halpern A, et al. Human-computer collaboration for skin cancer recognition. Nat Med 2020 Aug 22;26(8):1229-1234. [doi: 10.1038/s41591-020-0942-0] [Medline: $\underline{32572267]}$

104. Mosier K, Skitka L, Heers S, Burdick M. Automation bias: Decision making and performance in high-tech cockpits. Int J Aviat Psychol 1998;8(1):47-63. [doi: 10.4324/9781315095080-16]

105. Parasuraman R, Mouloua M, Molloy R. Effects of adaptive task allocation on monitoring of automated systems. Hum Factors 1996 Dec;38(4):665-679. [doi: 10.1518/001872096778827279] [Medline: 11536753]

106. Lyell D, Coiera E. Automation bias and verification complexity: a systematic review. J Am Med Inform Assoc 2017 Mar 01;24(2):423-431 [FREE Full text] [doi: 10.1093/jamia/ocw105] [Medline: 27516495]

107. Endsley M. Toward a theory of situation awareness in dynamic systems. Hum Factors 2016 Nov 23;37(1):32-64. [doi: $10.1518 / 001872095779049543]$

108. Kaber D, Endsley M. The effects of level of automation and adaptive automation on human performance, situation awareness and workload in a dynamic control task. Theor Issues Ergon Sci 2004 Mar;5(2):113-153. [doi: $10.1080 / 1463922021000054335]$

109. Kass S, Cole K, Stanny C. Effects of distraction and experience on situation awareness and simulated driving. Transport Res F Traffic Psychol Behav 2007 Jul;10(4):321-329. [doi: 10.1016/j.trf.2006.12.002]

110. Carlesi KC, Padilha KG, Toffoletto MC, Henriquez-Roldán C, Juan MAC. Patient safety incidents and nursing workload. Rev Lat Am Enfermagem 2017 Apr 06;25:e2841 [FREE Full text] [doi: 10.1590/1518-8345.1280.2841] [Medline: 28403334]

111. Fagerström L, Kinnunen M, Saarela J. Nursing workload, patient safety incidents and mortality: an observational study from Finland. BMJ Open 2018 Apr 24;8(4):e016367 [FREE Full text] [doi: 10.1136/bmjopen-2017-016367] [Medline: 29691240]

112. Koch S, Weir C, Haar M, Staggers N, Agutter J, Görges M, et al. Intensive care unit nurses' information needs and recommendations for integrated displays to improve nurses' situation awareness. J Am Med Inform Assoc 2012;19(4):583-590 [FREE Full text] [doi: 10.1136/amiajnl-2011-000678] [Medline: 22437074]

113. Fairbanks R, Caplan S. Poor interface design and lack of usability testing facilitate medical error. Joint Commiss J Qual Safety 2004 Oct;30(10):579-584. [doi: 10.1016/s1549-3741(04)30068-7]

114. Applying human factors and usability engineering to medical devices: guidance for industry and Food and Drug Administration staff. US Food and Drug Administration. 2016. URL: https://www.fda.gov/regulatory-information/ search-fda-guidance-documents/applying-human-factors-and-usability-engineering-medical-devices [accessed 2021-04-12]

115. van Berkel N, Clarkson MJ, Xiao G, Dursun E, Allam M, Davidson BR, et al. Dimensions of ecological validity for usability evaluations in clinical settings. J Biomed Inform 2020 Oct;110:103553. [doi: 10.1016/j.jbi.2020.103553] [Medline: 32891762]

116. Liu X, Faes L, Kale A, Wagner S, Fu D, Bruynseels A, et al. A comparison of deep learning performance against health-care professionals in detecting diseases from medical imaging: a systematic review and meta-analysis. Lancet Digital Health 2019 Oct;1(6):e271-e297. [doi: 10.1016/s2589-7500(19)30123-2]

117. van Smeden M, Van Calster B, Groenwold RHH. Machine learning compared with pathologist assessment. JAMA 2018 Apr 24;319(16):1725-1726. [doi: 10.1001/jama.2018.1466] [Medline: 29710156]

\section{Abbreviations}

AI: artificial intelligence

CBR: case-based reasoning

CCT: cognitive complexity theory

EHR: electronic health record

FDA: Food and Drug Administration

HFE: human factors and ergonomics

SEIPS: Systems Engineering Initiative for Patient Safety

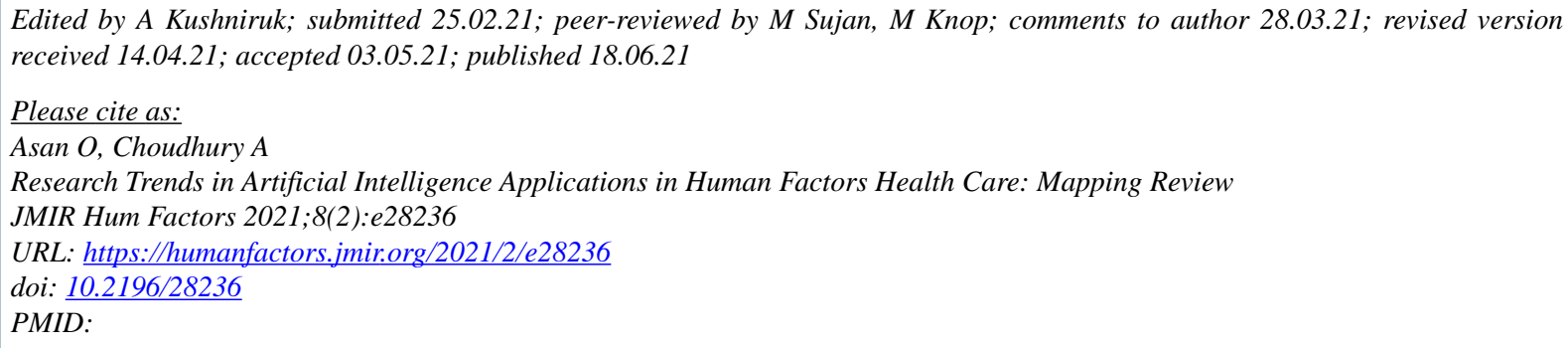


(C) Onur Asan, Avishek Choudhury. Originally published in JMIR Human Factors (https://humanfactors.jmir.org), 18.06.2021. This is an open-access article distributed under the terms of the Creative Commons Attribution License (https://creativecommons.org/licenses/by/4.0/), which permits unrestricted use, distribution, and reproduction in any medium, provided the original work, first published in JMIR Human Factors, is properly cited. The complete bibliographic information, a link to the original publication on https://humanfactors.jmir.org, as well as this copyright and license information must be included. 